\title{
Abordagem ambiental nos currículos dos cursos de engenharia de uma universidade do Sul do Brasil
}

A Constituição Brasileira de 1988 define, como incumbência do Poder Público, a promoção da Educação Ambiental (EA) em todos os níveis de ensino, bem como a conscientização pública para a preservação do meio ambiente. Há um interesse de que conteúdos nesta temática sejam debatidos e explorados em sala de aula, a fim de que os egressos, de várias áreas de formação, tenham capacidade de lidar com a legislação, normatizações e circunstâncias da área ambiental. O presente trabalho analisa a abordagem ambiental nas matrizes curriculares dos cursos de Engenharias da Universidade Federal de Pelotas (UFPEL), com o objetivo de compreender como são retratadas as questões ambientais nas suas disciplinas obrigatórias. A aquisição das informações foi realizada a partir das matrizes curriculares dos cursos, selecionando disciplinas que abordassem questões ambientais. Mediante a interpretação das ementas, procurou-se encontrar palavras que identificassem a abordagem dos temas ambientais apresentados, para que, por fim, essas disciplinas fossem agrupadas em três categorias distintas, levando como base a temática dos conteúdos. Foram selecionadas 29 disciplinas, em que 18 delas tem caráter obrigatório, das quais, a grande maioria, abordam aspectos conceituais e teóricos, de natureza introdutória, para embasamento de fundamentos sobre o tema. Foi possível identificar que todos os cursos de Engenharia analisados oferecem pelo menos uma disciplina que aborde questões ambientais, destacando-se a Engenharia Hídrica e a Agronomia que disponibilizam sete e seis disciplinas, respectivamente. Constatou-se que os cursos estão de acordo com o que propõe as Diretrizes Curriculares Nacionais do Ministério da Educação. Porém, destaca-se a necessidade de que os cursos ofereçam aos egressos disciplinas que contextualizem problemáticas ambientais na profissão, como por exemplo, no caso da Engenharia Civil, que não possibilita ao profissional contato com o conteúdo sobre resíduos sólidos. Nesse sentido, sugerimos a gestão da equipe de professores que compõe e constrói as matrizes curriculares dos cursos, a inclusão de temáticas e conteúdos específicos, propostos pela Instituição, constituindo conhecimentos necessários para garantir o desenvolvimento das competências e habilidades estabelecidas aos profissionais.

\section{Environmental approach in engineering course curricula at a university in southern Brazil}

\begin{abstract}
The Brazilian Constitution of 1988 defines, as incumbent upon the Government, the promotion of Environmental Education (EA) at all levels of education, as well as public awareness for the preservation of the environment. There is an interest that content on this subject is debated and explored in the classroom, so that graduates from various areas of education have the ability to deal with environmental legislation, regulations and circumstances. This paper analyzes the environmental approach in the curriculum matrices of the Engineering courses of the Federal University of Pelotas (UFPEL), aiming to understand how environmental issues are portrayed in their compulsory subjects. The acquisition of information was performed from the curriculum matrices of the courses, selecting subjects that addressed environmental issues. Through the interpretation of the menus, we tried to find words that identified the approach of the environmental themes presented, so that, finally, these disciplines were grouped into three distinct categories, based on the theme of the contents. Twenty-nine subjects were selected, 18 of which are compulsory, most of which address conceptual and theoretical aspects of an introductory nature to support the foundations on the subject. It was possible to identify that all Engineering courses analyzed offer at least one discipline that addresses environmental issues, with emphasis on Water Engineering and Agronomy that provide seven and six subjects, respectively. It was found that the courses are in accordance with what is proposed by the National Curriculum Guidelines of the Ministry of Education. However, there is a need for the courses to offer graduates disciplines that contextualize environmental issues in the profession, such as in the case of Civil Engineering, which does not allow the professional contact with solid waste content. In this sense, we suggest the management of the team of teachers who compose and build the curriculum matrices of the courses, the inclusion of specific themes and contents proposed by the Institution, constituting necessary knowledge to ensure the development of the competencies and skills established to the professionals.
\end{abstract}

Keywords: Curriculum matrices; Environmental education; National Curriculum Guidelines.

Topic: Planejamento, Gestão e Políticas Públicas Ambientais

Reviewed anonymously in the process of blind peer
Received: 12/03/2019

Approved: 19/06/2019
Viviane Rodrigues Dorneles

Universidade Federal de Pelotas, Brasil

http://lattes.cnpq.br/9960442005155624

vivianerdorneles2@gmail.com

Marco Antônio Simões de Souza

Instituto Federal Sul-Rio-Grandense, Brasil

http://lattes.cnpq.br/4704449376754914

marcoantoniopel@yahoo.com.br
Referencing this:

DORNELES, V. R.; SOUZA, M. A. S.. Abordagem ambiental nos currículos dos cursos de engenharia de uma universidade do Sul do Brasil. Natural Resources, v.9, n.2, p.43-58, 2019. DOI: http://doi.org/10.6008/CBPC2237-9290.2019.002.0005

DOI: 10.6008/CBPC2237-9290.2019.002.0005 


\section{INTRODUÇÃO}

Para alcançar uma sociedade que se estruture de maneira sustentável, é reconhecido pela comunidade ligada aos setores educacionais que a Educação Ambiental (EA) entre como uma ferramenta necessária para este fim. A EA, em termos de ensino, tem origem na década de 70, quando foi estabelecida como prática de conscientização, em função do movimento contemporâneo de ambientalização das mais variadas práticas sociais (FREITAS, 2012).

Nesse sentido, a EA atuaria na conscientização sobre problemática dos recursos naturais, bem como no fomento aos movimentos ecológicos, envolvendo as pessoas em ações sociais consideradas ambientalmente adequadas. Desta forma, inicia-se uma discussão em torno da necessidade prioritária da formação de professores aptos para formar o cidadão que, entre outras coisas, seja consciente de suas responsabilidades na sociedade (CARVALHO, 2004).

Aos poucos, a EA tem se constituído como proposta educativa, apresentada como uma nova dimensão incorporada ao processo educacional, por desenvolver discussões sobre questões ambientais. Porém, pesquisas mostram uma deficiente formação para a educação ambiental em instituições de ensino superior (FREITAS et al., 2012; FERRARO JÚNIOR, 2004), mesmo hoje sendo uma determinação legal e social a promoção de uma educação que comtemple a dimensão ambiental.

Servindo como amparo legal para argumentar a implementação de programas nesta temática, em qualquer nível de ensino, inclusive no ensino superior, a educação ambiental foi regulamentada pela Política Nacional da Educação Ambiental, publicada em 1999 pela Lei no9.795. Antes disso, em 1988, a Constituição Brasileira, já a trazia como uma ferramenta fundamental em todos os níveis de ensino, sendo o Poder Público responsável pela sua implementação e, da mesma forma, responsável pela conscientização pública para a preservação do meio ambiente (PEREIRA et al., 2009).

Do mesmo modo, a Lei de Diretrizes e Bases da Educação Nacional (Lei no9394/96), que incluiu a temática ambiental nos Parâmetros Curriculares Nacionais (PCN), foi um passo relevante que reconheceu a importância das questões ambientais nas matrizes curriculares dos cursos nas universidades brasileiras, ou simplesmente dentro das salas de aula da escola básica, em que a temática ambiental entrava como fundamental para educação (BRASIL, 1996).

Neste sentido, o Ministério da Educação juntamente com o Conselho Nacional de Educação publicou, em 2001, as Diretrizes Curriculares Nacionais dos Cursos de Engenharia (BRASIL, 2001). Esse documento, dentre outros fins, objetiva exercer a formação de um profissional capaz de propor soluções que não sejam apenas tecnicamente corretas, mas sim que tenha a ambição de considerar problemas em sua totalidade, considerando também a preocupação com a valorização e preservação do meio ambiente.

Nas Diretrizes Curriculares, o conceito de Currículo é substituído por um conceito bem mais amplo, que pode ser traduzido pelo "conjunto de experiências de aprendizado que o estudante incorpora durante o processo participativo de desenvolver um programa de estudos coerentemente integrado", substituindo o 
antigo conceito entendido como "grade curricular que formaliza a estrutura de um curso de graduação" (BRASIL, 2001).

Neste ponto, insere-se a possibilidade de incorporar cada vez mais as questões ambientais nas matrizes curriculares, seja no currículo formalmente explícito, como também nas práticas pedagógicas não explícitas, mas constituintes do chamado 'currículo oculto', fundamentais para a formação profissional, sendo de extrema importância, tendo em vista toda a preocupação com o meio ambiente.

A estruturação do currículo das Engenharias se dá em três áreas: um núcleo de conteúdos básicos que constitui cerca de $30 \%$ da carga horária mínima e que, dentre outros tópicos que podem ou não ser escolhidos pela Instituição, traz as Ciências Ambientais; um núcleo de conteúdos profissionalizante, abrangendo cerca de 15\% da carga horária mínima, e que traz a Gestão Ambiental como um dos seus tópicos; e por fim, um núcleo de conteúdos específicos, que caracterizam cada uma das modalidades das engenharias, o qual não especifica nenhum tópico nem relaciona a temática ambiental dentro dele (BRASIL, 2001).

A Universidade Federal de Pelotas (UFPEL) é umas das universidades referências no Sul do Brasil, localizada na cidade de Pelotas (RS). A UFPEL conta com 96 cursos de graduação, dentre eles, 12 cursos de Engenharia em diversas modalidades. Os cursos de engenharias e os profissionais formados neles, possuem um papel importante e único para a sociedade de, além de inovar, criando tecnologias para serem postas em prática, usar os conhecimentos para garantir a preservação dos bens naturais utilizados para a produção da vida humana.

Em vista disto, torna-se necessária uma atenção voltada à estruturação dos currículos destes cursos e à problemática ambiental a eles relacionada. Assim, é importante gerar panoramas e levantamentos a fim de subsidiar novas discussões e sobre as possíveis alternativas para a consolidação da temática ambiental na formação de engenheiros. Para contribuir nesta perspectiva, é interessante inicialmente que se compreenda como as questões ambientais são abordadas nesses cursos, evidenciando-se essa dimensão como fundamental para a formação dos profissionais.

Assim, procuramos encontrar indícios sobre a abordagem de conteúdos ligados à temática ambiental na formação dos engenheiros da UFPEL, por meio da análise das matrizes curriculares e ementas das disciplinas, que explicitamente fazem parte de currículos dos cursos. O objetivo desta pesquisa é analisar como, nas matrizes curriculares dos cursos de engenharia da UFPEL, são abordadas as questões ambientais em disciplinas obrigatórias.

\section{METODOLOGIA}

A pesquisa foi do tipo documental, elaborada levando como base os cursos de Engenharias da Universidade Federal de Pelotas (UFPEL). A Universidade está localizada no extremo sul do Estado do Rio Grande do Sul, Brasil, na cidade de Pelotas e foi fundada em 1969, possuindo hoje 22 unidades acadêmicas, contando com 96 cursos de graduação presencial, sendo 66 bacharelados, 22 licenciaturas, oito tecnólogos e três cursos de graduação a distância. A Universidade ainda oferece na pós-graduação 26 doutorados, 50 mestrados, seis cursos de mestrado profissional e 34 cursos de especialização. 
Dentre os cursos de graduação, a Universidade possui 12 cursos de Engenharia, sendo elas Engenharia Ambiental e Sanitária, Engenharia Agrícola, Engenharia Civil, Engenharia de Computação, Engenharia de Controle e Automação, Engenharia de Materiais, Engenharia de Petróleo, Engenharia de Produção, Engenharia Eletrônica, Engenharia Geológica, Engenharia Hídrica, Engenharia Industrial Madeireira, além de um curso de Agronomia, os quais são o enfoque deste trabalho.

Este trabalho consiste em um tratamento quantitativo, a fim de levantar o total de disciplinas que retratem a temática ambiental nos cursos de engenharias da UFPEL, e um tratamento qualitativo, com o intuito de conhecer de que forma as questões ambientais são tratadas nestas disciplinas e em qual temática esses assuntos são abordados. Para isso, foi realizado uma análise documental, com foco no currículo prescrito, dos cursos de engenharias. Estes currículos são disponibilizados no site da universidade (portal.ufpel.edu.br). A coleta dos dados se deu a partir das informações de 2018/1, que foram coletadas dia 21 de março de 2018.

Com base no que foi levantado, as informações das disciplinas ambientais das matrizes curriculares dos cursos de engenharia da UFPEL foram organizadas numa planilha eletrônica. Esta planilha continha o curso do qual a disciplina faz parte, o nome da disciplina, o semestre em que é ministrada, o código da disciplina (a fim de verificar semelhança entre cursos), o caráter da disciplina (se ela é ofertada como optativa ou obrigatória) e a quantidade de créditos/horas.

Assim, foi realizado o levantamento em 11 matrizes curriculares de cursos de engenharia da UFPEL, sendo que entre eles também foi analisado o curso de Agronomia, por ser um curso considerado como engenharia agronômica em muitas universidades, e que a partir disto aqui também será identificado como engenharia. A tabela 1 apresenta os cursos de engenharias analisados da UFPEL, as unidades acadêmicas que eles estão inseridos, os turnos que as aulas são ministradas e a quantidade de semestres letivos.

Tabela 1: Cursos de Engenharia analisados da Universidade Federal de Pelotas (UFPEL), unidades acadêmicas, seus respectivos turnos das aulas e semestres letivos.

\begin{tabular}{|c|c|c|c|}
\hline Curso & Unidade Acadêmica & Turno & Semestres \\
\hline Agronomia & Faculdade de Agronomia Eliseu Maciel & Integral & 9 \\
\hline Engenharia Agrícola & Centro de Engenharias & Integral & 10 \\
\hline Engenharia Civil & Centro de Engenharias & Integral & 10 \\
\hline Curso & Unidade Acadêmica & Turno & Semestres \\
\hline Engenharia de Controle e Automação & Centro de Engenharias & Integral & 10 \\
\hline Engenharia Eletrônica & Centro de Engenharias & Integral & 10 \\
\hline Engenharia Geológica & Centro de Engenharias & Integral & 10 \\
\hline Engenharia Hídrica & Centro de Desenvolvimento Tecnológico & Integral & 10 \\
\hline Engenharia Industrial Madeireira & Centro de Engenharias & Integral & 10 \\
\hline Engenharia de Materiais & Centro de Desenvolvimento Tecnológico & Integral & 10 \\
\hline Engenharia de Petróleo & Centro de Engenharias & Integral & 10 \\
\hline Engenharia de Produção & Centro de Engenharias & Noturno & 10 \\
\hline
\end{tabular}

Foram considerados 11 cursos de Engenharia, sendo todos na modalidade de bacharelado e presenciais. Com exceção do curso de Agronomia, que disponibiliza 9 semestres, os demais apresentam 10 semestres letivos, em que, para maioria dos cursos, o último semestre é ofertado somente para elaboração do trabalho de conclusão. Todos os cursos são de turno integral, exceto a Engenharia de Produção que é 
noturno, porém também presencial. O curso de Engenharia Ambiental e Sanitária não foi avaliado, uma vez que este é um curso com enfoque total na área ambiental.

A logística para obter todas as informações necessárias se deu em três etapas. A primeira foi a identificação e seleção, nas matrizes curriculares, das disciplinas, obrigatórias e optativas, que abordem questões ambientais, nos cursos de engenharia. Posteriormente, separamos as disciplinas optativas das obrigatórias, considerando, para as etapas seguintes, somente as disciplinas obrigatórias, pois são as essas que todos os egressos efetivamente terão contato, diferentemente das optativas, que o aluno pode selecionar por opção qual delas gostaria de se aperfeiçoar.

A segunda etapa se deu na leitura e interpretação das ementas das disciplinas obrigatórias, procurando encontrar palavras que identificassem, de alguma forma, a abordagem de temas ambientais, tais como: meio ambiente, educação ambiental, gestão ambiental, poluição, reciclagem, resíduos, conservação, sustentabilidade, impactos ambientais, recuperação, entre outras.

Por fim, a terceira etapa consistiu no estabelecimento de relações, feita pela classificação das disciplinas obrigatórias de acordo com a natureza das abordagens, a fim de sistematizar posteriores discussões. Esta etapa agrupou as disciplinas em três categorias: a categoria 1 são as disciplinas de enfoque mais conceitual e de aspectos teóricos; a categoria 2 contemplou disciplinas com aspectos de avaliação e diagnóstico; e a categoria 3 seriam as disciplinas de concepção mais técnica de execução e tomadas de decisão.

\section{RESULTADOS}

A partir do levantamento de informações das disciplinas ambientais nas matrizes curriculares dos cursos de engenharia da UFPEL, foram selecionadas preliminarmente 29 disciplinas (dentre obrigatórias e optativas), incluídas nos cursos, consideradas como disciplinas que proporcionem temas com alguma abordagem ambiental.

Dentre essas disciplinas inicialmente selecionadas, 18 delas estão incluídas nas matrizes curriculares como disciplinas obrigatórias, são elas: 'Meio ambiente e desenvolvimento', 'Engenharia civil e qualidade ambiental', 'Habitabilidade e sustentabilidade nas construções', 'Ecologia e impacto ambiental', 'Biomateriais', 'Direito ambiental e dos recursos hídricos', 'Saúde, meio ambiente e segurança (SMS) no setor do petróleo', 'Princípios da Agroecologia', 'Resíduos na indústria de base madeireira', 'Engenharia ambiental', 'Saneamento rural e gestão ambiental', 'Avaliação de impactos ambientais no setor do petróleo', 'Gestão Ambiental', 'Sistema de Gestão Ambiental', 'Conforto ambiental para edificações agrícolas', 'Diagnósticos e controle de impactos ambientais', 'Manejo e conservação do solo' e 'Recuperação de áreas degradadas'.

As demais são ofertadas como disciplinas optativas, sendo elas: 'Cartografia Ambiental', 'Controle ambiental na indústria de celulose e papel', 'Energia e meio ambiente', 'Fontes alternativas de energia', 'Gestão Ambiental dos resíduos orgânicos gerados nos sistemas de produção agropecuários', 'Gestão de 
Resíduos', 'Impactos ambientais no aproveitamento de recursos hídricos', 'Legislação mineral e ambiental', 'Licenciamento ambiental', 'Reciclagem dos materiais' e 'Reuso da água'.

Neste sentido, a oferta de uma maior quantidade de disciplinas obrigatórias, comparativamente às optativas, é uma realidade significativa quando se trata desta temática, uma vez que, a partir do momento que se tem um número maior de disciplinas obrigatórias, nas matrizes curriculares das engenharias, aponta um direcionamento para que o profissional em formação tenha contato com o conteúdo proposto, diferentemente daquelas optativas ofertadas, em que nem todo egresso terá relação com o tema. A tabela 2 apresenta as disciplinas, optativas e obrigatórias selecionadas que abordam questões ambientais, integrantes das matrizes curriculares dos cursos de engenharias da UFPEL, o semestre em que elas são ministradas, seus respectivos códigos, caráter, créditos e horas e o curso em que estão inseridas.

Tabela 2: Disciplinas ambientais inseridas nas matrizes curriculares dos cursos de Engenharias da Universidade Federal de Pelotas (UFPEL).

\begin{tabular}{|c|c|c|c|c|c|c|}
\hline № & Disciplinas & Semestre & Código & Caráter & Créd. /Horas & Curso \\
\hline 1 & $\begin{array}{l}\text { Avaliação de impactos ambientais no setor do } \\
\text { petróleo }\end{array}$ & $3^{\circ}$ & 1640321 & Obrigatória & $4 / 68$ & Eng. Petróleo \\
\hline 2 & Biomateriais & $8^{\circ}$ & 950030 & Obrigatória & $4 / 68$ & Eng. Materiais \\
\hline 3 & Cartografia Ambiental & - & 800072 & Optativa & $4 / 68$ & Eng. Geológica \\
\hline 4 & Conforto ambiental para edificações agrícolas & $7^{\circ}$ & 570081 & Obrigatória & $4 / 68$ & Eng. Agrícola \\
\hline 5 & $\begin{array}{l}\text { Controle ambiental na ind. De celulose e } \\
\text { papel }\end{array}$ & - & 570168 & Optativa & $4 / 68$ & Eng. Industrial Madeireira \\
\hline 6 & $\begin{array}{l}\begin{array}{l}\text { Diagnósticos e controle de impactos } \\
\text { ambientais }\end{array} \\
\end{array}$ & $9^{\circ}$ & 1630021 & Obrigatória & $2 / 34$ & Eng. Civil \\
\hline № & Disciplinas & Semestre & Código & Caráter & Créd. /Horas & Curso \\
\hline 7 & Direito ambiental e dos recursos hídricos & $6^{\circ}$ & 960038 & Obrigatória & $2 / 34$ & Eng. Hídrica \\
\hline \multirow{2}{*}{8} & \multirow{2}{*}{ Ecologia e impacto ambiental } & $3^{\circ}$ & 950045 & Obrigatória & $2 / 34$ & Eng. Materiais \\
\hline & & 20 & 960002 & Obrigatória & $2 / 34$ & Eng. Hídrica \\
\hline 9 & Energia e meio ambiente & - & 960068 & Optativa & $3 / 51$ & Eng. Hídrica \\
\hline 10 & Engenharia ambiental & $9^{\circ}$ & 1640064 & Obrigatória & $4 / 68$ & Eng. Produção \\
\hline 11 & Engenharia civil e qualidade ambiental & $1^{\circ}$ & 570164 & Obrigatória & $2 / 34$ & Eng. Civil \\
\hline 12 & Fontes alternativas de energia & - & 960071 & Optativa & $3 / 51$ & Eng. Hídrica \\
\hline 13 & $\begin{array}{l}\text { Gestão Amb. Resíd. Orgânicos dos sist. Prod. } \\
\text { Agropecuários }\end{array}$ & - & 240072 & Optativa & $4 / 68$ & Agronomia \\
\hline \multirow{2}{*}{14} & \multirow{2}{*}{ Gestão Ambiental } & - & 570128 & Optativa & $4 / 68$ & Eng. Agrícola \\
\hline & & $8^{\circ}$ & 50109 & Obrigatória & $3 / 51$ & Agronomia \\
\hline 15 & Gestão de Resíduos & - & 960073 & Optativa & $3 / 51$ & Eng. Hídrica \\
\hline 16 & $\begin{array}{l}\text { Habitabilidade e sustentabilidade nas } \\
\text { construções }\end{array}$ & $6^{\circ}$ & 1630004 & Obrigatória & $3 / 51$ & Eng. Civil \\
\hline 17 & $\begin{array}{l}\text { Impactos ambientais no aproveitamento de } \\
\text { recursos hídricos }\end{array}$ & - & 960059 & Optativa & $3 / 51$ & Eng. Hídrica \\
\hline 18 & Legislação Mineral e ambiental & - & 800071 & Optativa & $4 / 68$ & Eng. Geológica \\
\hline 19 & Licenciamento ambiental & - & 50110 & Optativa & $3 / 51$ & Agronomia \\
\hline 20 & Manejo e conservação do solo & $8^{\circ}$ & 230027 & Obrigatória & $4 / 68$ & Agronomia \\
\hline \multirow{4}{*}{21} & \multirow{4}{*}{ Meio ambiente e desenvolvimento } & $1^{\circ}$ & 570132 & Obrigatória & $2 / 34$ & Eng. Agrícola \\
\hline & & $10^{\circ}$ & 570132 & Obrigatória & $2 / 34$ & $\begin{array}{l}\text { Eng. Controle e } \\
\text { Automação }\end{array}$ \\
\hline & & $10^{\circ}$ & 570132 & Obrigatória & $2 / 34$ & Eng. Eletrônica \\
\hline & & $1^{\circ}$ & 570132 & Obrigatória & $2 / 34$ & Eng. Industrial Madeireira \\
\hline 22 & Princípios da Agroecologia & $5^{\circ}$ & 230030 & Obrigatório & $4 / 68$ & Agronomia \\
\hline 23 & Reciclagem dos materiais & - & 950032 & Optativa & $3 / 51$ & Eng. de Materiais \\
\hline \multirow{2}{*}{24} & \multirow{2}{*}{ Recuperação de áreas degradadas } & $8^{\circ}$ & 1640191 & Obrigatória & $4 / 68$ & Eng. Geológica \\
\hline & & - & 230040 & Optativa & $3 / 51$ & Agronomia \\
\hline 25 & Resíduos na indústria de base madeireira & $7^{\circ}$ & 570124 & Obrigatória & $4 / 68$ & Eng. Industrial Madeireira \\
\hline 26 & Reuso da água & - & 960063 & Optativa & $3 / 51$ & Eng. Hídrica \\
\hline 27 & Saneamento rural e gestão ambiental & $8^{\circ}$ & 570125 & Obrigatória & $4 / 68$ & Eng. Agrícola \\
\hline 28 & $\begin{array}{l}\text { Saúde, meio ambiente e segurança (SMS) no } \\
\text { setor do petróleo }\end{array}$ & $9^{\circ}$ & 1640227 & Obrigatória & $4 / 68$ & Eng. Petróleo \\
\hline
\end{tabular}


Observa-se na tabela 2 que a maioria das disciplinas então inseridas somente em um curso de engenharias, apresentando como exceção a disciplina de Ecologia e impacto ambiental, inserida nos cursos de Engenharia de Materiais e Hídrica, a disciplina de Gestão ambiental, optativa na Engenharia Agrícola e obrigatória na Agronomia, a disciplina de Meio Ambiente e Desenvolvimento, dos cursos de Engenharia Agrícola, Controle e Automação, Eletrônica e Industrial Madeireira e a disciplina de Recuperação de Áreas Degradadas, na Engenharia Geológica e Agronomia. As demais disciplinas que contemplam mais de um curso estão inseridas no máximo em dois cursos.

A partir da lista acima, destaca-se a inclusão da disciplina de Meio ambiente e Desenvolvimento em vários cursos analisados. Esta disciplina tem apenas dois créditos, ou seja, 34 horas semestrais e contempla temas de aspectos mais conceituais como conceitos básicos sobre meio ambiente, a questão ambiental, o histórico da relação meio ambiente versus desenvolvimento, conceitos básicos sobre o desenvolvimento sustentável e ética e cidadania.

Com base na tabela 2, podemos observar também que, dentre os cursos analisados, a Engenharia Hídrica é o curso que contempla mais disciplinas ambientais, possuindo sete disciplinas, em que duas são ofertadas como obrigatórias e cinco como optativas. Da mesma forma, o curso de Agronomia, também apresenta na sua matriz curricular, um elevado número de disciplinas ambientais ofertadas, comparativamente com os demais cursos. Este curso contempla seis disciplinas nessa área, em que três disciplinas são ofertadas como obrigatórias e três como optativas. Os demais cursos oferecem entre uma a quatro disciplinas ambientais.

Outra análise que pode ser feita a partir das informações da tabela 2 é o principal semestre em que essas disciplinas ambientais são ofertadas. No caso para os cursos analisados, o semestre que contempla mais disciplinas ofertadas é o oitavo, seguido do nono e do primeiro. Torna-se interessante observar em qual etapa da formação do engenheiro essas disciplinas são ministradas, pois isto está diretamente ligado com a relação que o aluno terá com a disciplina, a quantidade de suporte de conhecimento ele já tem para receber o novo conteúdo, ao grau de aprendizado que terá, juntamente com o estágio de maturidade do estudante para estudar tal conteúdo.

O número de créditos e a carga horária das disciplinas ambientais também são parâmetros importantes a serem analisados. Diante dos resultados da Tabela 2 observamos que a maioria das disciplinas (16), sendo obrigatórios ou optativas, possuem 4 créditos, ou seja, 68 horas semestrais, as demais, 10 possuem 3 créditos totalizando 51 horas e por fim cinco disciplinas possuem 2 créditos com 34 horas semestrais. Esses dois fatores são relevantes para argumentação estruturação do currículo e para as questões ambientais abordadas. Evidentemente, quanto mais créditos a disciplina ambiental possuir, maior será o contato do educando com a proposta, e presumivelmente maiores possibilidades terá de estabelecer relações de sua atuação profissional com as questões ambientais.

Com a leitura e interpretação das ementas das disciplinas obrigatórias, procuramos encontrar palavras que identificam a abordagem dos temas ambientais. Assim, foi realizada uma classificação das 
disciplinas de acordo com a natureza das abordagens. Como explicado anteriormente, a Categoria 1 agrupou as disciplinas de caráter mais conceitual e de aspectos teóricos, a Categoria 2 as disciplinas com aspectos de avaliação e diagnóstico e a Categoria 3 são as disciplinas com aspectos mais técnicos de execução e tomadas de decisão. A tabela 3 apresenta as disciplinas ambientais que se enquadraram nas categorias supracitadas e os respectivos cursos que integram.

Tabela 3: disciplinas classificadas como Categoria 1 conceituais e de aspecto teórico, Categoria 2 avaliação e diagnóstico e Categoria 3 técnicas de execução e os cursos que as contemplam.

\begin{tabular}{|l|l|l|}
\hline \multicolumn{1}{|c|}{ Categoria } & \multicolumn{1}{|c|}{ Disciplinas } & \multicolumn{1}{c|}{ Cursos } \\
\hline \multirow{5}{*}{ Meio ambiente e desenvolvimento } & $\begin{array}{l}\text { Eng. Agrícola } \\
\text { Eng. de Controle e Automação } \\
\text { Eng. Eletrônica } \\
\text { Eng. Industrial Madeireira }\end{array}$ \\
\cline { 2 - 3 } & Engenharia civil e qualidade ambiental & Eng. Civil \\
\cline { 2 - 3 } & Habitabilidade e sustentabilidade nas construções & Eng. Civil \\
\cline { 2 - 3 } & Ecologia e impacto ambiental & $\begin{array}{l}\text { Eng. de Materiais } \\
\text { Eng. Hídrica }\end{array}$ \\
\cline { 2 - 3 } & Biomateriais & Eng. de Materiais \\
\cline { 2 - 3 } & Direito ambiental e dos recursos hídricos & Eng. Hídrica \\
\cline { 2 - 3 } & Saúde, meio ambiente e segurança (SMS) no setor do petróleo & Eng. Petróleo \\
\cline { 2 - 3 } & Princípios da Agroecologia & Agronomia \\
\cline { 2 - 3 } & Resíduos na indústria de base madeireira & Eng. Industrial Madeireira \\
\cline { 2 - 3 } & Engenharia ambiental & Eng. da Produção \\
\hline \multirow{5}{*}{ Exaliação e Diagnóstico } & Eng. Agrícola \\
\cline { 2 - 3 } & Saneamento rural e gestão ambiental & Eng. Petróleo \\
\cline { 2 - 3 } & Avaliação de impactos ambientais no setor do petróleo & Agronomia \\
\cline { 2 - 3 } & Gestão Ambiental & Eng. Industrial Madeireira \\
\cline { 2 - 3 } & Sistema de Gestão Ambiental & Eng. Agrícola \\
\hline & Conforto ambiental para edificações agrícolas & Eng. Civil \\
\cline { 2 - 3 } & Diagnósticos e controle de impactos ambientais & Agronomia \\
\cline { 2 - 3 } & Manejo e conservação do solo & Eng. Geológica \\
\cline { 2 - 3 } & Recuperação de áreas degradadas & \\
\hline
\end{tabular}

Diante do exposto na Tabela 3, notamos que, dentre as 18 disciplinas obrigatórias totais, dez delas, ou seja, mais da metade integram a Categoria 1. Neste sentido, destacamos que a abordagem principal das disciplinas ambientais ofertadas nos cursos de Engenharia da UFPEL seria de caráter mais introdutório, para embasamento de fundamentos sobre o tema, e não focado em problemas ambientais específicos. Nesta perspectiva, ao analisar os cursos que contemplam disciplinas selecionadas nesta categoria, observamos que, dos 11 cursos de engenharia analisados, 10 reúnem disciplinas na Categoria 1, com exceção somente do curso de Engenharia Geológica que não apresentou disciplinas neste contexto.

As disciplinas inseridas na Categoria 1 dispõem de conteúdos mais conceituais e teóricos, retratando conteúdos como a parte de normas regulamentadoras, para orientações sobre procedimentos obrigatórios relacionados ao tema, a fim de direcionar os futuros profissionais a atuar dentro da legalidade, dentro dos parâmetros de regulamentação. Da mesma forma, as disciplinas da Categoria 1 envolvem conteúdos introdutórios, de inicialização aos demais temas propostos, como conceitos básicos, princípios, dando embasamento a conjuntos normativos ou padrões de conduta a serem seguidos, e pontos considerados iniciais para determinado assunto ou questão.

Semelhantemente, algumas disciplinas da Categoria 1 abrangem também o histórico e fundamentos das questões ambientais, no âmbito mundial e de considerações nacionais, apresentando aspectos da Lei, 
como por exemplo a Política Nacional do Meio Ambiente, Sistemas Nacionais e a parte de Legislação Ambiental, entre outros. Ou seja, essas disciplinas não tratam de formação de valores, mas somente com fatos, leis, regras, técnicas. Observa-se na tabela 3 que, das 18 disciplinas obrigatórias selecionadas, quatro se encaixaram na Categoria 2, das quais estão inseridas nos cursos de Engenharia Agrícola, Engenharia de Petróleo, Agronomia e Engenharia Industrial Madeireira. Nesta categoria encaixam-se disciplinas que ofereçam conteúdos para avaliação e diagnóstico na temática ambiental.

Essas disciplinas pretendem contribuir na formação do egresso fornecendo conhecimentos técnicos, metodológicos, legais e práticos de análise ambiental. Também suas ementas colaboram para que o egresso se habilite em analisar e interpretar os processos que contemplam e afetam o contexto ambiental. Além disso, essas disciplinas abrangem conteúdos que oferecem interpretação, avaliação, gestão, planejamento, implantação, gerenciamento, estratégias, diagnóstico e planos para área ambiental. Esse planejamento de ação é fundamentado não somente em informações técnicas, mas consciência sobre o impacto de sua ação. Beneficiar populações humanas, proteger a diversidade ambiental, por exemplo, são valores que embasarão decisões técnicas, e não somente os fatores econômicos, como é muitas vezes destacado nas engenharias e outros cursos nas áreas tecnológicas.

Por fim, observa-se na tabela 3 que os cursos de Engenharia Agrícola, Civil, Agronomia e Geológica contemplam as quatro disciplinas que se encaixaram na Categoria 3. As disciplinas desta categoria pretendem passar conteúdos mais de execução técnica, como a parte de controle ambiental, desinfestação e tratamento ambiental. Também a parte de métodos, ações mitigadoras e de recuperação ambiental, processos de execução, reabilitação, remediação e prevenção de área degradadas. Essas disciplinas também englobam temáticas sobre a utilização de técnicas específicas, manejo conservacionista, instrumentação, e pôr fim a parte de monitoramento ambiental e acompanhamento técnico científico.

\section{DISCUSSÃO}

A partir do levantamento realizado nas matrizes curriculares dos cursos de engenharias da UFPEL, foi possível verificar que $62 \%$ (18) das disciplinas totais com abordagem ambiental levantadas são ofertadas pelos cursos em caráter obrigatório, o que expressa uma condição que o profissional em formação tenha contato com o conteúdo proposto, tornando-se interessante do ponto de vista de requisitos para o egresso. Neste sentido, Sorrentino (1995) discute que as ações mais comuns adotadas por algumas Universidades para promoção das questões ambientais têm sido mesmo a incorporação de disciplinas, que tenham como objetivo a abordagem da educação ambiental na Universidade.

Segundo Sorrentino (1995), isto é importante frente a formação didática, científica, técnica e humanística do profissional para exercer a profissão em defesa da vida, do ambiente e do bem-estar dos cidadãos. Ou seja, garante-se pelo menos a abertura de um espaço que possibilite a discussão ambiental. $O$ quanto essa discussão vai avançar envolve muitos outros fatores, dependendo do perfil formativo e sensibilização tanto dos professores como dos alunos que cursarão essas disciplinas. 
Thomaz (2006) argumenta que alguns pesquisadores são favoráveis à criação de uma disciplina específica de Educação Ambiental nos cursos de Ensino Superior, do que não ofertar conteúdos disciplinares relacionados, pois "indicam que o desenvolvimento de forma interdisciplinar da educação ambiental é um ideal e que criar uma disciplina obrigatória para os cursos, atualmente, seria mais interessante para que todos os estudantes tenham uma base sólida sobre a temática".

Diante dos resultados deste trabalho verificou-se que não é ofertado, nos cursos considerados, uma disciplina específica de sobre educação ambiental, mas sim disciplinas ambientais básicas, sendo estas, a maioria do total (Categoria 1). O conhecimento ambiental, assim construído, é essencial para a formação do egresso e deve preparar esse profissional para trabalhar de forma eficiente esse importante tema transversal. No entanto, foi visto que a presença da dimensão ambiental ainda é incipiente em alguns cursos, como por exemplo na Engenharia de controle e automação, Engenharia de produção e Engenharia eletrônica que apresentaram somente uma disciplina ambiental em todo o currículo.

Uma das razões pelas quais existe uma pequena quantidade de disciplinas ofertadas pode ser a falta de conhecimento a respeito da legislação pela Lei 9.795/1999, que institui a Política Nacional de Educação Ambiental (PNEA). Pesquisas apontam que a PNEA é desconhecida por muitos professores. Ao analisarem a incorporação da dimensão ambiental em dez cursos da Universidade Regional de Blumenau, Verdi et al. (2006) verificaram que $32 \%$ dos 136 professores entrevistados que lecionam nesses cursos não conhecem a PNEA. Para os autores, "apesar dos esforços desprendidos pelos Ministérios da Educação e do Meio Ambiente, a PNEA ainda é pouco conhecida e atendida" (VERDI et al. 2006).

Para Thomaz et al. (2007), embora exista uma legislação que assegure o tratamento das questões ambientais no currículo, a incorporação no Ensino Superior, é um processo demorado e depende da capacitação de todos os profissionais envolvidos. Fica claro desta maneira que, para a implementação das Diretrizes Curriculares Nacionais da Educação Ambiental, o corpo docente deveria ter o conhecimento prévio dos preceitos estabelecidos pela PNEA. É possível ressaltar alguns pontos da resolução (BRASIL, 2012)

Art. 1. inciso II: Estimular a reflexão crítica e propositiva da inserção da Educação Ambiental na formulação, execução e avaliação dos projetos institucionais e pedagógicos das instituições de ensino, para que a concepção de Educação Ambiental como integrante do currículo supere a mera distribuição do tema pelos demais componentes;

Art. 5o: A Educação Ambiental não é atividade neutra, pois envolve valores, interesses, visão de mundo e desse modo deve assumir na prática educativa, de forma articulada e interdependente, as suas dimensões política e pedagógica.

Reigota (1994) reforça essa ideia, esclarecendo que a educação ambiental deve ser definitivamente compreendida como uma educação política, preparando cidadãos capacitados a entender o porquê fazer algo, não se detendo apenas no como fazer, ou seja, enfatizando o componente reflexivo, tão importante quanto $o$ ativo.

Lopes et al. (2012), ao investigar sobre a inclusão da dimensão ambiental no curso de Pedagogia da Unesp/Araraquara (SP) verificou, a partir da análise dos programas de ensino das disciplinas obrigatórias, que das 42 disciplinas oferecidas, apenas duas $(4,8 \%)$ podem ser consideradas que abordem diretamente conteúdos ambientais, o que está longe de atender às exigências da PNEA, quanto à inserção da temática 
em todas as disciplinas. Este resultado também pode indicar desconhecimento da legislação ou até mesmo falta de compreensão da importância do tema para a formação dos futuros professores.

Nos cursos analisados neste trabalho, que ofertam essas disciplinas ambientais, outro aspecto importante de se discutir é em que etapa da formação dos engenheiros essas disciplinas são ministradas. Foi verificado que o semestre que contempla mais disciplinas ofertadas é o oitavo e nono, ou seja, no quarto e quinto ano de formação. Dentro desta linha, Sacristán et al. (1998) defende que "a chave da aprendizagem significativa está na vinculação substancial das novas ideias e conceitos com a bagagem cognitiva do indivíduo", sendo a bagagem todo aquele conjunto de vivências e conteúdos já adquiridos durante a formação e vida.

Neste aspecto, conteúdos ambientais serem ministrados da metade ao final do curso é interessante, do ponto de vista que o aluno associe o conteúdo ambiental a outro tema, ou até mesmo a prática que ele já vivenciou, aumentando, assim, a absorção do conteúdo como aprendizagem. Segundo Sacristán et al. (1998), cada aluno capta a significação do conteúdo novo em função das peculiaridades historicamente construídas de sua estrutura cognitiva. A potencialidade significativa do conteúdo encontra-se subordinada em cada indivíduo às características de sua bagagem cognitiva. Deste modo, o planejamento didático de todo processo de aprendizagem significativa deve começar por conhecer a peculiar estrutura ideativa e mental do indivíduo que realizará as tarefas de aprendizagem.

A principal abordagem nas disciplinas ambientais dos cursos de engenharia da UFPEL são conteúdos de caráter mais introdutório (Categoria 1). Esses conteúdos se caracterizam em introduzir o aluno ao tema ambiental apresentando seus conceitos mais básicos, principais segmentos e aplicações, além de uma visão geral da sua história. Os tópicos abordados nestas disciplinas pretendem servir como introduções específicas para cada tema desenvolvido no curso, bem como termologias básicas e conceitos gerais utilizados no decorrer do curso.

Pereira et al. (2009), ao analisar o conteúdo de 701 disciplinas, de 22 cursos de química, em 16 universidades públicas do sudeste do Brasil, identificaram que apenas um pequeno número (23) de disciplinas mostrou uma relação explícita entre as atividades humanas e o meio ambiente. Um total de 11 disciplinas teóricas e 193 experimentais exploraram, até certo ponto, aspectos científicos e tecnológicos relacionados ao meio ambiente, mas não incluíram sua relação com a sociedade. Como as disciplinas experimentais supostamente incluem algum tipo de tratamento de resíduos, isso pode explicar por que os professores de química do ensino médio trabalham principalmente em programas de reciclagem e resíduos em suas escolas, mostrando como a formação, a partir dos conteúdos propostos nos cursos, forma e molda os profissionais que deles são egressos.

Dos cursos considerados neste trabalho, cinco deles somente ofertam disciplinas que foram categorizadas na categoria 1 (Engenharia de controle e automação, Engenharia materiais, Engenharia produção, Engenharia eletrônica e Engenharia hídrica). Reflete-se, a partir disso, que se não for do interesse do aluno buscar outras disciplinas, sejam optativas ou até mesmo fora do curso, o egresso apenas terá a visão básica da temática ambiental, não entrando em conteúdos e temas específicos, e que se reflete, a 
quando o profissional vir a trabalhar com a temática ambiental em sua atuação profissional por exemplo, que possivelmente replicará o que foi visto, como discutido anteriormente por Pereira et al. (2009).

Diante disso, pode-se discutir que essas disciplinas teóricas e conceituais são importantes, mas pouco contribuem para a formação dos engenheiros no aspecto prático. Elas fornecem ao estudante fundamentos para entender os propósitos da temática ambiental, dando-Ihe os elementos para o desenvolvimento conceitual ambiental e oferece conhecimentos básicos para estes tipos de atividades. Em cada curso analisado a abordagem dos aspectos ambientais se dá de forma diferente. Os cursos de Engenharia agrícola e Agronomia são os únicos que disponibilizam ao aluno disciplinas que se enquadram nas três categorias deste trabalho, ou seja, o egresso tem acesso tanto a conceitos teóricos básicos, quanto a parte avaliação e de execução técnica.

A Agronomia é um dos cursos com mais disciplinas que abordam questões ambientais oferecidas, que no total, considerando obrigatórias e optativas, disponibiliza ao aluno seis disciplinas ambientais. Este curso traz, no seu Projeto Pedagógico, vários propósitos ambientais, além da temática ambiental estar bem explicita no seu objetivo geral em que mostra que:

\begin{abstract}
A formação acadêmica plena de um Engenheiro-Agrônomo de sólida cultura e visão holística da atividade agrícola, sendo capaz de desenvolver trabalho técnico e economicamente viável, ecologicamente apropriado, socialmente justo e solidário, credenciando-se assim para atuar e ser sujeito do processo agrícola, contribuindo efetivamente para o desenvolvimento rural sustentável.
\end{abstract}

Já o curso de Engenharia Agrícola é o único entre os analisados que disponibiliza um documento próprio de Diretrizes Curriculares Nacionais do curso de Engenharia Agrícola (BRASIL, 2004). Isto pode explicar a amplitude dos conteúdos das disciplinas e a abrangência dos aspectos ambientais na sua matriz curricular. Neste documento está explícita a responsabilidade do egresso em resolver problemas, considerando aspectos políticos, econômicos, sociais, ambientais e culturais, com visão ética e humanística, em atendimento às demandas da sociedade. As diretrizes do curso trazem que o profissional deve ter contato com conteúdos específicos sobre a temática ambiental em que:

O curso de Engenharia Agrícola deverá estabelecer ações pedagógicas com base no desenvolvimento de condutas e atitudes com responsabilidade técnica e social, tendo como princípios: a) respeito à fauna e à flora; b) conservação ou recuperação da qualidade do solo, do ar e da água; c) uso tecnológico racional, integrado e sustentável do ambiente; d) emprego de raciocínio reflexivo, crítico e criativo; e) atendimento às expectativas humanas e sociais no exercício de atividades profissionais.

Por outro lado, como citado anteriormente, ao contrário do que foi discutido sobre o curso de Agronomia e Engenharia Agrícola, os cursos de Engenharia de Controle e Automação, Engenharia materiais, Engenharia produção, Engenharia eletrônica e Engenharia Hídrica somente ofertam disciplinas que se encaixam na categoria 1. Destaca-se, ainda, que a Engenharia Hídrica é o curso que mais disponibiliza disciplinas que abordem questões ambientais, em que, entre obrigatórias e optativas, oferta sete disciplinas ambientais, das quais apenas duas são de caráter obrigatórios e ambas de aspecto conceitual e teórico.

Para Engenharia do petróleo, que disponibiliza duas disciplinas ambientais, e Engenharia Industrial madeireira, que oferta três disciplinas neste âmbito, essas disciplinas enquadram-se tanto em aspectos conceituais quanto na parte de avaliação. Diante disso, os egressos desses cursos, além de dispor todo 
embasamento dos fundamentos e conceitos ambientais, também saem com uma ampla experiência para avaliação e diagnóstico na temática ambiental. Além disso, os egressos obtêm conhecimentos técnicos, metodológicos, legais e práticos de análise ambiental e habilidade em analisar os processos que afetam o contexto ambiental.

O Ministério da Educação, em 2001, publicou as Diretrizes Curriculares Nacionais dos Cursos de Engenharia (BRASIL, 2001). Esse documento, dentre outros fins, objetiva auxiliar a exercer uma formação de um profissional capaz de propor soluções que não sejam apenas tecnicamente corretas, mas sim que tenha a ambição de considerar problemas em sua totalidade, considerando também a preocupação com a valorização e preservação do meio ambiente. Este documento também traz a amplitude do que deve ser a formação de um profissional das áreas das engenharias e prevê que

As tendências atuais vêm indicando na direção de cursos de graduação com estruturas flexíveis, permitindo que o futuro profissional a ser formado tenha opções de áreas de conhecimento e atuação, articulação permanente com o campo de atuação do profissional, base filosófica com enfoque na competência, abordagem pedagógica centrada no aluno, ênfase na síntese e na transdisciplinaridade, preocupação com a valorização do ser humano e preservação do meio ambiente, integração social e política do profissional, possibilidade de articulação direta com a pós-graduação e forte vinculação entre teoria e prática.

Essas diretrizes, da mesma forma, apresentam o perfil desejado do egresso que é formado a partir dos cursos de Engenharias, em que o curso compreenderá uma sólida formação técnico científica e profissional geral que o capacite a absorver e desenvolver novas tecnologias, estimulando a sua atuação crítica e criativa na identificação e resolução de problemas, considerando seus aspectos políticos, econômicos, sociais, ambientais e culturais, com visão ética e humanística, em atendimento às demandas da sociedade.

As diretrizes apresentam de que forma deve ser realizada a estruturação do currículo das engenharias. Esta estruturação se dá em três núcleos de conteúdos. Todo o curso de engenharia, independente de sua modalidade, deve possuir em seu currículo um núcleo de conteúdos básicos, um núcleo de conteúdos profissionalizantes e um núcleo de conteúdos específicos que caracterizará cada modalidade.

O núcleo de conteúdos básicos constitui cerca de 30\% da carga horária mínima que, dentre 14 outros tópicos como matemática, física, química, expressão gráfica, informática, entre outros, traz um de Ciências Ambientais que pode ou não ser escolhido pela Instituição. Da mesma forma, as diretrizes trazem um núcleo de conteúdos profissionalizante que acarreta cerca de 15\% da carga horária mínima, do qual traz a Gestão Ambiental como um dos seus tópicos, dentre os 52 outros, em que esses tópicos também são definidos pela instituição. E por fim, um núcleo de conteúdos específicos, que caracterizam cada uma das modalidades das engenharias, o qual não especifica nenhum tópico nem relaciona a temática ambiental dentro dele (BRASIL, 2001). Esse núcleo de conteúdos específicos se constitui em

Extensões e aprofundamentos dos conteúdos do núcleo de conteúdos profissionalizantes, bem como de outros conteúdos destinados a caracterizar modalidades. Estes conteúdos, consubstanciando o restante da carga horária total, serão propostos exclusivamente pela instituição. Constituem-se em conhecimentos científicos, tecnológicos e instrumentais necessários para a definição das modalidades de engenharia e devem garantir o desenvolvimento das competências e habilidades estabelecidas nestas diretrizes. 
Relacionando o que é disposto nas diretrizes e o que pôde ser observado com o levantamento deste trabalho, é que as diretrizes trazem como sugestão que no núcleo básico e profissionalizante seja inserido do currículo um tópico de ciências ambientais e gestão ambiental, respectivamente. Porém, não especifica, para nenhum dos tópicos descritos, o que deve ser efetivamente discutido nestes conteúdos. Visto que todos os cursos de engenharias considerados nesta pesquisa apresentam em sua matriz curricular uma disciplina que aborde a temática ambiental, seja por aspectos básicos, avaliativos ou de execução, pode-se constatar que esses cursos estão de acordo com o que é proposto pela legislação.

Ainda, além de todos os cursos analisados disponibilizarem pelo menos uma disciplina obrigatória que aborde as questões ambientais, na sua matriz curricular, os currículos ainda trazem a possibilidade de o aluno selecionar disciplinas optativas para cursar. Em todos os cursos analisados, para que o aluno obtenha o título da graduação, é exigido que curse entre 110 a 350 horas de atividades livres e complementares, dependendo dos critérios de cada curso, nas quais entram as disciplinas optativas. Estas informações estão disponibilizadas nos Projetos Pedagógicos de cada curso.

De fato, na UFPEL, o aluno tem obrigação de escolher e fazer disciplinas optativas para cumprir o número de horas mínimo estabelecido. Isto favorece ao aluno uma formação mais ampla, pois este é autônomo para escolher as disciplinas optativas para usufruir, que não são ofertadas como obrigatórias, mas são da mesma forma importantes para sua formação. Neste sentido, pode-se destacar, a partir do levantamento, que seis cursos analisados (Agronomia, Engenharia agrícola, Engenharia industrial madeireira, Engenharia geológica, Engenharia de materiais e Engenharia hídrica) disponibilizam disciplinas optativas que abordam questões ambientais, o que serve de complemento para formação ambiental do egresso.

Os cursos que não oferecem disciplinas ambientais optativas (Engenharia de petróleo, Engenharia de controle e automação, Engenharia de produção, Engenharia eletrônica e Engenharia civil) não descartam que o aluno tenha contato a temática discutida. $\mathrm{O}$ aluno ainda tem a possibilidade de escolher fazer as disciplinas optativas de outros cursos por exemplo, e posteriormente pedir o aproveitamento desses créditos para complementar a carga horária necessária de atividades complementares.

Isto também é discutido nas Diretrizes (BRASIL, 2001) em que na nova definição de currículo, destacam-se três elementos fundamentais para o entendimento da proposta aqui apresentada. Em primeiro lugar, enfatiza-se o conjunto de experiências de aprendizado. Entende-se, portanto, que currículo vai muito além das atividades convencionais de sala de aula e deve considerar atividades complementares, tais como iniciação científica e tecnológica, programas acadêmicos amplos, programas de extensão universitária, visitas técnicas, eventos científicos, além de atividades culturais, políticas e sociais, dentre outras, desenvolvidas pelos alunos durante o curso de graduação. Essas atividades complementares podem ser também a seleção de disciplinas optativas, e visam ampliar os horizontes de uma formação profissional, proporcionando uma formação sociocultural mais abrangente.

Mediante o diagnóstico realizado nas matrizes curriculares, dos cursos de engenharias da UFPEL, três questões vieram à tona, e serão comentadas a seguir. Uma dessas, que foi observada, foi a inexistência de uma disciplina que trate especificamente de questões sobre resíduos sólidos, principalmente nos cursos de 
Engenharia civil, Engenharia de produção e Engenharia de materiais. Neste sentido, a disciplina de Gerenciamento e tratamento de resíduos sólidos, por exemplo, é disponibilizada no curso de Engenharia Sanitária e Ambiental. O importante a ser destacado é que o aluno tenha conhecimento de disciplinas optativas de outros cursos, que podem ser cursadas mediante matrícula especial.

Outro aspecto que pode ser destacado neste sentido é a pouca disponibilidade da disciplina de Legislação Ambiental. Esta é apenas ofertada em caráter optativo pelo curso de Agronomia. Porém, o conhecimento da legislação ambiental e de aspectos importantes das normas legais relacionadas é um importante instrumento para a proteção do meio ambiente, sendo esta legislação vasta e complexa, e seu cumprimento de fundamental importância. Todavia, as questões sobre legislação e normas foram identificadas em várias das ementas das disciplinas. Ou seja, este assunto é abordado dentro de outras disciplinas além da disciplina de legislação ambiental.

Por fim, percebeu-se também a necessidade de considerar, além da disponibilidade de disciplinas ambientais, do caráter em que essas são ofertadas e a abordagem ambiental vista, a formação e preparação dos professores que ministram essas disciplinas ambientais. Nesse sentido, é considerada prioritária a formação de professores aptos a atuarem como agentes de mudanças ambientais e as instituições de ensino superior desenvolverem um papel fundamental para incorporação da educação ambiental nos níveis de ensino. Ficaria aqui a sugestão de uma pesquisa complementar a esta desenvolvida, com o objetivo de identificação da formação e preparo técnico científico desses professores que ministram essas disciplinas ambientais.

\section{CONSIDERAÇÕES FINAIS}

Retomando os resultados obtidos nesta investigação, destacamos que uma maior quantidade de disciplinas ambientais obrigatórias foi verificada comparativamente as optativas. Vinte e nove disciplinas, dentre optativas e obrigatórias, foram consideradas com abordagem de questões ambientais nos cursos de engenharias da Universidade Federal de Pelotas. Destas, dezoito são ofertadas com caráter obrigatório, principalmente no oitavo e nono semestre, com carga horária de 68 horas semestrais. A grande maioria é enquadrada na categoria 1 , de disciplinas mais conceituais e de aspectos teóricos, incluídas na maioria dos cursos, com exceção somente do curso de Engenharia Geológica. As demais (8) foram encaixadas na categoria 2, (4) de aspectos avaliativos e na categoria 3, (4) de execução técnica. 0 curso de Engenharia Hídrica e Agronomia são os cursos com maior número de disciplinas ofertadas.

Neste sentido, a oferta de uma maior quantidade de disciplinas obrigatórias, comparativamente as optativas, é uma realidade significativa quando se trata desta temática, uma vez que, a partir do momento que se tem um número maior de disciplinas obrigatórias, nas matrizes curriculares das engenharias, apontase um direcionamento para que o profissional em formação tenha contato com o conteúdo proposto, diferentemente daquelas optativas ofertadas, em que nem todo egresso terá relação com o tema.

Diante do levantamento realizado, sugerimos atenção a uma disciplina sobre Resíduos Sólidos, bem como uma sobre Legislação Ambiental. Da mesma forma, para posteriores trabalhos, a consideração da 
formação dos professores que ministram esse tipo de disciplina poderia ser discutida, de maneira a contemplar tanto aspectos técnicos como de sensibilização para a problemática ambiental.

Salientamos que as questões ambientais consistem não somente em disseminar informações sobre a problemática ambiental, mas também sensibilizar o meio acadêmico para atuarem na busca de soluções para essa problemática. Nesse sentido, além de informar, busca formar o profissional de Engenharia, para contribuir para o desenvolvimento da vida humana e não-humana em sua atuação.

\section{REFERÊNCIAS}

BRASIL. Diretrizes Curriculares Nacionais do Curso de Engenharia Agrícola. Brasília: MEC, 2004.

BRASIL. Diretrizes Curriculares Nacionais dos Cursos de Engenharia. Brasília: MEC, 2001.

BRASIL. Lei n.9394 de 20 de dezembro de 1996. Dispõe sobre as Diretrizes e Bases da Educação Nacional. Brasília: DOU, 1996.

BRASIL. Resolução n.2 de 15 de junho de 2012. Estabelece as Diretrizes Curriculares Nacionais para a Educação Ambiental. Brasília: MEC, 2012.

CARVALHO, M. C. M.. Educação Ambiental: a formação do sujeito ecológico. 6 ed. São Paulo: Cortez, 2004.

FERRARO JÚNIOR, L. A.. A universidade e a formação do educador ambiental: uma breve reflexão sobre as experiências da Universidade Estadual de Feira de Santana UEFS. Revista Brasileira de Educação Ambiental, São Paulo, n.1, p.116-119, 2004.

FREITAS, D.; SOUZA, M. L.. O ensino superior no Brasil: desafios para a ambientalização curricular. In: LEME, P. C. S.; PAVESI, A.; ALBA, D.; GONZÁLEZ, M. J. D.. Visões e experiências ibero-americanas de sustentabilidade nas universidades. Alhambra, Madri, p.129-135, 2012.

LOPES, T. M.; ZANCUL, M. C. S.. A temática ambiental no curso de Pedagogia de uma universidade pública paulista.
Pesquisa em Educação Ambiental, São Paulo, v.7, n.1 p.154-166, 2012. DOI: http://doi.org/10.18675/2177580X.vol7.n1.p154-166

PEREIRA, J. B.; CAMPOS, M. L. A. M.; NUNES, S. M. T.; ABREU, D. G.. Um panorama sobre a abordagem ambiental no currículo de cursos de formação inicial de professores de química na região sudeste. Química Nova, São Paulo, v.32, n.2, p.511-517, 2009. DOI: http://doi.org/10.1590/S010040422009000200040

REIGOTA, M.. O que é educação ambiental. São Paulo: Brasiliense, 1994.

SACRISTÁN, J. G.; GÓMEZ, A. I. P.. Compreender e transformar o ensino. 4 ed. Porto Alegre: ArtMed, 1998.

THOMAZ, C. E.. Educação Ambiental na Formação Inicial de Professores. Dissertação (Mestrado em Educação) Pontifícia Universidade Católica, Campinas, 2006.

THOMAZ, C. E.; CAMARGO, D. M. P.. Educação ambiental no Ensino Superior: Múltiplos Olhares. Revista Eletrônica do Mestrado em Educação Ambiental, Rio Grande, v.18, p.313318, 2007. DOI: https://doi.org/10.14295/remea.v18i0.3555

VERDI, M.; PEREIRA, G. R.. Educação Ambiental na Formação de Educadores: O Caso da Universidade Regional de Blumenau - FURB. Revista Eletrônica do Mestrado em Educação Ambiental, Rio Grande, v.17, p.375-391, 2006. DOI: https://doi.org/10.14295/remea.v17i0.3093

A CBPC - Companhia Brasileira de Produção Científica (CNPJ: 11.221.422/0001-03) detém os direitos materiais desta publicação. Os direitos referem-se à publicação do trabalho em qualquer parte do mundo, incluindo os direitos às renovações, expansões e disseminações da contribuição, bem como outros direitos subsidiários. Todos os trabalhos publicados eletronicamente poderão posteriormente ser publicados em coletâneas impressas sob coordenação da Sustenere Publishing, da Companhia Brasileira de Produção Científica e seus parceiros autorizados. Os (as) autores (as) preservam os direitos autorais, mas não têm permissão para a publicação da contribuição em outro meio, impresso ou digital, em português ou em tradução. 